\title{
Risks Involved in the Use of Enrofloxacin for Salmonella Enteritidis or Salmonella Heidelberg in Commercial Poultry
}

\begin{abstract}
Eduardo Morales-Barrera', Nicole Calhoun', Jose L. Lobato-Tapia', Vivian Lucca ${ }^{3}$, Omar Prado-Rebolledo ${ }^{4}$, Xochitl Hernandez-Velasco ${ }^{5}$, Ruben Merino-Guzman ${ }^{5}$, Victor M. Petrone-García ${ }^{6}$, Juan D. Latorre ${ }^{2}$, Brittany D. Mahaffey², Kyle D. Teague ${ }^{2}$, Lucas E. Graham², Amanda D. Wolfenden², Mikayla F. A. Baxter', Billy M. Hargis² and Guillermo Tellez ${ }^{2 *}$
\end{abstract}

\section{OPEN ACCESS \\ Edited by: \\ Ryan Arsenault, \\ University of Delaware, USA \\ Reviewed by: \\ Christi Swaggerty, \\ United States Department of Agriculture, USA \\ Bradley L. Bearson, \\ United States Department of Agriculture, USA \\ *Correspondence: Guillermo Tellez gtellez@uark.edu}

Specialty section: This article was submitted to Veterinary Infectious Diseases,

a section of the journal

Frontiers in Veterinary Science

Received: 06 June 2016 Accepted: 19 August 2016 Published: 31 August 2016

Citation: Morales-Barrera E, Calhoun N, Lobato-Tapia JL, Lucca V, Prado-Rebolledo O, Hernandez-

Velasco $X$, Merino-Guzman R,

Petrone-García VM, Latorre JD,

Mahaffey $B D$, Teague $K D$,

Graham $L E$, Wolfenden $A D$,

Baxter MFA, Hargis BM and Tellez G (2016) Risks Involved in the Use of Enrofloxacin for Salmonella Enteritidis or Salmonella Heidelberg in Commercial Poultry. Front. Vet. Sci. 3:72. doi: 10.3389/fvets.2016.00072
'Departamento de Producción Agrícola y Animal, Universidad Autónoma Metropolitana, Mexico City, México, ${ }^{2}$ Department of Poultry Science, University of Arkansas, Fayetteville, AR, USA, ${ }^{3}$ Departamento de Medicina Veterinaria, Centro de Ciencias Rurais, Universidade Federal de Santa Maria, Santa Maria, Brazil, ${ }^{4}$ Facultad de Medicina Veterinaria y Zootecnia, Universidad de Colima, Colima, México, ${ }^{5}$ Facultad de Medicina Veterinaria y Zootecnia, Universidad Nacional Autónoma de México, Ciudad de México, México, ${ }^{6}$ Departamento de ciencias pecuarias, Facultad de Estudios Superiores Cuautitlán UNAM, Cuautitlán, México

The objectives of the present study were to evaluate the risks involved in the use of Enrofloxacin for Salmonella Enteritidis (SE) or Salmonella Heidelberg (SH) in commercial poultry and determine the effects of a probiotic as an antibiotic alternative. Two experiments were conducted to evaluate the risks involved in the use of Enrofloxacin for SE or SH in commercial poultry. Experiment 1 consisted of two trials. In each trial, chickens were assigned to one of three groups; control + SE challenged; Enrofloxacin $25 \mathrm{mg} / \mathrm{kg}+\mathrm{SE}$; and Enrofloxacin $50 \mathrm{mg} / \mathrm{kg}+\mathrm{SE}$. Chickens received Enrofloxacin in the drinking water from days 1 to 5 of age. On day 6 , all groups received fresh water without any treatment. All chickens were orally gavaged with $10^{7} \mathrm{cfu} / \mathrm{chick}$ of SE at 7 days of age and euthanized on 8 days of age. In Experiment 2, turkey poults were assigned to one of the three groups; control $+\mathrm{SH}$; probiotic $+\mathrm{SH}$; and Enrofloxacin $50 \mathrm{mg} / \mathrm{kg}+\mathrm{SH}$. Poults received probiotic or Enrofloxacin in the drinking water from days 1 to 5 of age. On day 6 , poults received fresh water without any treatment. Poults were orally gavaged with $10^{7} \mathrm{cfu} /$ poult of $\mathrm{SH}$ at 7 days of age. Poults were weighed and humanely killed $24 \mathrm{~h}$ post-SH challenge to evaluate serum concentration of fluorescein isothiocyanate-dextran to evaluate intestinal permeability, metagenomics, and SH infection. In both trials of Experiment 1, chickens treated with Enrofloxacin were more susceptible to SE organ invasion and intestinal colonization when compared with control non-treated chickens $(P<0.05)$. In Experiment 2, poults treated with $50 \mathrm{mg} / \mathrm{kg}$ of Enrofloxacin showed an increase in body weight, however, this group also showed an increase in SH susceptibility, intestinal permeability, and lower proportion of Firmicutes and Bacteroidetes, but with control group had the highest proportion of Proteobacteria. By contrast, poults that received the probiotic had the highest proportion of Firmicutes and Bacteroidetes, but lowest Proteobacteria. The results of the present study suggest 
that prophylactic utilization of Enrofloxacin at five times the recommended dose in poultry increases the susceptibility to salmonellae infections, and confirms that probiotics may be an effective tool in salmonellae infections.

Keywords: Enrofloxacin, Salmonella, poultry, susceptibility, metagenomics

\section{INTRODUCTION}

Fluoroquinolones are the third generation of quinolone development. Nalidixic acid and pipemidic acid are examples of the first generation and currently have limited activity against Gram-negative bacteria. Fluorinated 4-quinolones were introduced to the market in the 1980s and were the top of the line antibiotics, offering a broad spectrum of activity and high efficacy in a wide range of infections both orally and parenterally $(1,2)$. Nevertheless, history has demonstrated that the extensive use of new antibiotics is eventually shadowed by the appearance of resistance to those chemicals that have become a major global problem. This was demonstrated by the higher incidence of salmonellae and Campylobacter infections worldwide, and several reports of fluoroquinolone resistance in clinical isolates for these and other enteric pathogens (3-7). Hence, the World Health Organization (WHO) published a list of antibiotics that should be reserved for human use only (8), and fluoroquinolones were among them, due to the alarming evidence of quinolone-resistant zoonotic pathogens. Soon after the publication of the WHO report, several countries banned the use of fluoroquinolones in animal production (9-11). With growing consumer and scientific pressures, the European Union went one step further, creating new legislations banning the use of all antibiotics as growth promoters as of January 2006 (12). However, in many countries, the indiscriminate use and misuse of antibiotics, including fluoroquinolones, are still a sad reality. Especially in countries where there is no legislation regulating the use of fluoroquinolones in animal agriculture and where there is an abundance of generic fluoroquinolones at a low cost. Typical management practices in those countries are to treat or dose healthy neonatal chickens and turkey poults with five times the recommended dose of Enrofloxacin for five consecutive days in the drinking water. Interestingly, in those countries, the incidence of Salmonella spp. and Campylobacter spp. rates in both humans and agriculture are also high $(1,13-16)$. Therefore, the objectives of the present study were to evaluate and confirm the risks involved in the use of Enrofloxacin for Salmonella enterica serovars Enteritidis or Heidelberg in commercial poultry and to determine if poultry selected probiotics have a prophylactic effect when birds are challenged with SE and $\mathrm{SH}$.

\section{MATERIALS AND METHODS}

\section{Enrofloxacin}

Baytril $^{\circledR}$ (Bayer Health Care LLC, Mission, KS 66201, USA) Enrofloxacin 3.23\% concentrate solution for use in chickens and turkeys drinking water only.

\section{Probiotic Culture}

FloraMax ${ }^{\circledR}$-B11 (Pacific Vet Group USA Inc., Fayetteville, AR 72703 , USA) is a defined probiotic culture derived from gastrointestinal poultry origin that contains proprietary strains of lactic acid bacteria (LAB), selected by their in vitro ability to inhibit enteropathogens (17).

\section{Animal Source}

Day-of-hatch, male broiler chickens were obtained from CobbVantress (Siloam Springs, AR, USA) for Experiment 1 or male turkey poults from a local hatchery in Experiment 2 and were randomly housed in heated brooder batteries in a controlled age-appropriate environment. For each experiment, birds were provided ad libitum access to water, and unmedicated cornsoybean diet, meeting the nutritional requirements of poultry recommended by National Research Council (18), respectively. All animal handling procedures were in compliance with Institutional Animal Care and Use Committee at the University of Arkansas. In each experiment, a small number of chicks or poults $(n=10)$ were humanely euthanized upon arrival by $\mathrm{CO}_{2}$ asphyxiation. Ceca-cecal tonsils (CCT), liver, and spleen were aseptically cultured in tetrathionate enrichment broth (Catalog no. 210420, Becton Dickinson, Sparks, MD, USA). Enriched samples were confirmed negative for Salmonella by streak plating the samples on Xylose Lysine Tergitol-4 (XLT-4, Catalog no. 223410, BD Difco ${ }^{\mathrm{TM}}$ ) selective media.

\section{Bacterial Strains and Culture Conditions}

The challenge organism used in Experiment 1 was a poultry isolate of Salmonella enterica serovar Enteritidis (SE), bacteriophage type 13A, obtained from the USDA National Veterinary Services Laboratory, Ames, IA, USA. In Experiment 2, a primary poultry isolate of Salmonella enterica serovar Heidelberg (SH) isolated in our laboratory was used. Antimicrobial susceptibility test revealed that both isolates were sensitive to Enrofloxacin. Furthermore, SE and SH are resistant to $25 \mu \mathrm{g} / \mathrm{mL}$ of novobiocin (NO, catalog no.N-1628, Sigma) and were selected for resistance to $20 \mu \mathrm{g} / \mathrm{mL}$ of nalidixic acid (NA, catalog no.N-4382, Sigma) in our laboratory. For both experiments, $100 \mu \mathrm{L}$ of SE or SH from a frozen aliquot was added to $10 \mathrm{~mL}$ of tryptic soy broth (Catalog no. 22092, Sigma) and incubated at $37^{\circ} \mathrm{C}$ for $8 \mathrm{~h}$, and passed three times every $8 \mathrm{~h}$ to ensure that all bacteria were in $\log$ phase. Post-incubation, bacterial cells were washed three times with sterile $0.9 \%$ saline by centrifugation at $1,864 \times g$ for $10 \mathrm{~min}$, reconstituted in saline, quantified by densitometry with a spectrophotometer (Spectronic 20D+, Spectronic Instruments Thermo Scientific), and diluted to an approximate concentration of $10^{8} \mathrm{cfu} /$ milliliter. Concentrations of SE or SH were further verified by serial dilution and plating on brilliant green agar (BGA, 
Catalog no. 70134, Sigma) with NO and NA for enumeration of actual cfu used to challenge the chickens and turkeys.

\section{Experimental Design in Chickens and Turkeys}

\section{Evaluation of Enrofloxacin in Neonatal Chickens} Challenged with Salmonella Enteritidis. Experiment 1

Two independent trials were conducted. In each trial, 36 chickens were randomly assigned to one of three groups $(n=12)$ : control SE challenged without Enrofloxacin; Enrofloxacin $25 \mathrm{mg} / \mathrm{kg} \mathrm{SE}$ challenged; and Enrofloxacin $50 \mathrm{mg} / \mathrm{kg}$ SE challenged. Chickens received Enrofloxacin from days 1 to 5 of age in the drinking water. At day 6, treated groups received fresh water without any treatment. Fresh water without antibiotic was administered to control chickens throughout the experiment. All chickens were orally gavaged with $10^{7} \mathrm{cfu} / \mathrm{chick}$ of SE at 7 days of age. Chickens were humanely euthanized for culture at 8 days of age as describe below.

\section{Salmonella Recovery}

At 8 days, broilers were humanely euthanized and liver and spleen were collected aseptically and enriched in $10 \mathrm{~mL}$ of tetrathionate broth (Becton Dickinson) overnight at $37^{\circ} \mathrm{C}$. Following enrichment, each sample was streaked for isolation on BGA plates containing $25 \mu \mathrm{g} / \mathrm{mL}$ of $\mathrm{NO}$ and $20 \mu \mathrm{g} / \mathrm{mL}$ of NA. The plates were incubated at $37^{\circ} \mathrm{C}$ for $24 \mathrm{~h}$ and examined for the presence or absence of antibiotic-resistant SE. CCT were collected aseptically, homogenized within sterile sample bags (Nasco, Fort Atkinson, WI, USA) using a rubber mallet and diluted with saline (1:4 by $\mathrm{wt} / \mathrm{vol}$ ) and 10 -fold dilutions were plated on BGA with NO and $\mathrm{NA}$, incubated at $37^{\circ} \mathrm{C}$ for $24 \mathrm{~h}$ to enumerate total SE colony forming units. The CCT samples were enriched in $2 \times$ concentrated tetrathionate enrichment broth and further incubated at $37^{\circ} \mathrm{C}$ for $24 \mathrm{~h}$ to enrich. Following this, enrichment samples were plated on BGA with $\mathrm{NO}$ and NA and incubated at $37^{\circ} \mathrm{C}$ for $24 \mathrm{~h}$ to confirm presence/absence of typical lactose-negative colonies of Salmonella.

\section{Evaluation of Prophylactic Administration of FloraMax-B11 ${ }^{\circledR}$ Enrofloxacin in Neonatal Turkey Poults Challenged with Salmonella Heidelberg. Experiment 2}

In Experiment 2, 72 day-of-hatch turkey poults were neck tagged, weighed, and randomly assigned to one of the three groups $(n=24 /$ group): control SH challenged without treatment; probiotic SH challenged; and Enrofloxacin $50 \mathrm{mg} / \mathrm{kg} \mathrm{SH}$ challenged. Poults received FloraMax-B1 $1^{\circledast}$ or Enrofloxacin from days 1 to 5 of age in the drinking water. Control group received fresh water without any treatment throughout the duration of the experiment. At day 6, treated groups received water without any treatment. All poults were orally gavaged with $10^{7} \mathrm{cfu} /$ poult of $\mathrm{SH}$ at 7 days of age. Poults were weighed and humanely euthanized $24 \mathrm{~h}$ post-SH challenge (day 8 of age) to evaluate serum concentration of fluorescein isothiocyanate-dextran (FITC-D) and cecal bacterial community compositions as describe below, as well as Salmonella recovery and plating from CCT as was previously described. Samples from CCT were also plated in Man Rogosa
Sharpe (Difco ${ }^{\mathrm{TM}}$ Lactobacilli MRS Agar VWR Cat. No. 90004084 Suwanee, GA 30024) to evaluate total number of LAB.

\section{Serum Determination of FITC-D Leakage}

Intestinal leakage of FITC-D (MW 3-5 KDa; Sigma-Aldrich Co., St. Louis, MO, USA) and the measurement of its serum concentration were done in experiment 2 as a marker of paracellular transport and mucosal barrier dysfunction (19-22). At $24 \mathrm{~h}$, post$\mathrm{SH}$ challenge (day 8 of age), poults in all groups were given an oral gavage dose of FITC-D $(4.16 \mathrm{mg} / \mathrm{kg})$. Following $2.5 \mathrm{~h}$, they were killed by $\mathrm{CO}_{2}$ asphyxiation. Blood samples were collected from the femoral vein kept at room temperature for $3 \mathrm{~h}$ and centrifuged $(500 \times g$ for $15 \mathrm{~min})$ to separate the serum from the red blood cells. FITC-D levels of diluted serum samples (1:5 PBS) were measured at excitation wavelength of $485 \mathrm{~nm}$ and an emission wavelength of $528 \mathrm{~nm}$ with a Synergy HT, Multi-mode microplate fluorescence reader (BioTek Instruments, Inc., Vermont, USA). Fluorescence measured was then compared to a standard curve with known FITC-D concentrations. Gut leakage for each bird was reported as microgram of FITC-D/mL of serum (20).

\section{DNA Extraction and Illumina-Based Analysis of Microbial Community Diversity}

Cecal content from six poults was obtained, homogenized thoroughly in four volumes diluent $(0.85 \% \mathrm{NaCl}, 0.1 \%$ peptone $)$, centrifuged at $300 \times g$ for 2 min to remove large debris, and finally, $0.5 \mathrm{~mL}$ of aliquots (average $8 \mathrm{mg}$ dry weight) were pelleted at $10,000 \times g$ for $5 \mathrm{~min}$. Extraction of DNA was performed immediately using the QIAamp DNA Stool Mini Kit (QIAGEN, Hilden, Germany). Bacterial community compositions at Phylum and Class level were performed using Illumina dye sequencing (Era7 Bioinformatics Inc., Cambridge, MA 02142, USA). The analysis corresponded to $16 \mathrm{~S}$ rRNA amplicons from V6 region sequenced with Illumina technology (23). Reads were assigned to a taxon based on sequence similarity to 16S rRNA genes extracted from the NCBI nt database. The $16 \mathrm{~S}$ rRNA sequences were extracted from NCBI based on their presence in the set of sequences included in the Ribosomal Database Project (RDP) (24) and on the specificity of their taxonomical assignment based on the lowest common ancestor (LCA) approach adopted metagenomics analysis as the last version of Meta-Genome Analyzer (MEGAN). The algorithm was similar to the assignment algorithm adopted by MEGAN tool (25). Phylum distribution in all the samples is expressed in \% on the total merged reads of each sample.

\section{Data and Statistical Analysis}

$\log _{10} \mathrm{cfu} / \mathrm{g}$ of SE and SH in cecal contents, body weight (BW), body weight gain (BWG), serum FITC-D concentration, and proportion of bacterial composition were subjected to analysis of variance as a completely randomized design, using the General Linear Models procedure of SAS (26). Significant differences among the means were determined by Duncan's multiple-range test at $P<0.05$. Enrichment data were expressed as positive/ total chickens (\%), and the percent recovery of SE and SH was compared using the chi-squared test of independence, testing all possible combinations to determine the significance $(P \leq 0.05)$ for these studies (27). 
TABLE 4 | Phylum distribution (cumulative \% lowest common ancestor) and class direct assignment in $\%$ for all ceca samples of turkey poults following prophylactic administration of FloraMax-B11 ${ }^{\circledR}$ or Enrofloxacin.

\begin{tabular}{|c|c|c|c|}
\hline & Control + SH & $\begin{array}{l}\text { FloraMax- } \\
\text { B11 }^{\circledR}+\text { SH }\end{array}$ & $\begin{array}{c}\text { Enrofloxacin } \\
50 \mathrm{mg} / \mathrm{kg}+\mathrm{SH}\end{array}$ \\
\hline \multicolumn{4}{|l|}{ Phylum } \\
\hline Firmicutes & $42 \pm 10^{b}$ & $55 \pm 8^{a}$ & $9 \pm 4^{c}$ \\
\hline Bacteroidetes & $19 \pm 6^{a}$ & $23 \pm 4^{\mathrm{a}}$ & $10 \pm 2^{b}$ \\
\hline Proteobacteria & $29 \pm 4^{a}$ & $18 \pm 5^{b}$ & $31 \pm 3^{a}$ \\
\hline \multicolumn{4}{|l|}{ Class } \\
\hline Gammaproteobacteria & $15.07 \pm 2.58^{\mathrm{a}}$ & $6.16 \pm 0.083^{b}$ & $24.95 \pm 2.76^{a}$ \\
\hline Clostridia & $5.01 \pm 2.22^{\mathrm{a}}$ & $4.25 \pm 1.30^{\mathrm{a}}$ & $2.40 \pm 0.04^{b}$ \\
\hline Bacilli & $3.05 \pm 0.01^{a}$ & $4.21 \pm 0.01^{\mathrm{a}}$ & $1.11 \pm 0.06^{b}$ \\
\hline
\end{tabular}

Experiment 2.

a,b Superscripts within rows indicate significant difference at $P<0.05, n=6$.

the antibiotic. Furthermore, significant increases in the proportion of Proteobacteria were observed in poults that received Enrofloxacin or control poults when compared with poults that received FloraMax-B $11^{\circledR}$. At the class level, it was interesting to observe that both control and Enrofloxacin poults had an increase in Gammaproteobacteria, but Clostridia and Bacilli were decreased in Enrofloxacin birds when compared with control or poults treated with the probiotic (Table 4).

\section{DISCUSSION}

Considerable scientific evidence has shown that the use of certain antibiotics increases enteric colonization of antibiotic-resistant strains of enteric pathogens in domestic animals (28-32). Because some of these pathogens are extremely resistant to many antibiotics and are capable of rapidly developing resistance when exposed $(7,13,14)$, antibiotic prophylaxis or treatment has been reported to actually increase the occurrence and severity of these infections in commercial poultry $(33,34)$. In addition, the lack of effect of these antibiotics in resistant enteropathogens, some researchers have shown that antibiotics can actually cause disruption in the microbiome (35), accompanied with reduction of short chain fatty acids $(36,37)$ and increased luminal $\mathrm{pH}$ in the distal gastrointestinal tract (38). In the present study, we evaluate the management practice in certain countries of using five times the recommended dose of Enrofloxacin in neonatal chickens and turkey poults for five consecutive days after placement, and look at their susceptibility to salmonellae infections $24 \mathrm{~h}$ after treatment. In trial 1 of Experiment 1, chickens treated with either 25 or $50 \mathrm{mg} / \mathrm{kg}$ of Enrofloxacin were more susceptible to SE organ invasion when compared with control non-treated chickens. In addition, chickens treated with $50 \mathrm{mg} / \mathrm{kg}$ of Enrofloxacin in trial 1 and both Enrofloxacin doses in trial 2 had a significant increase in total SE cfu in cecae when compared with control chickens, suggesting that this management practice performed in poor antimicrobial stewardship countries, increased susceptibility to SE infections in broiler chickens.

Salmonella Heidelberg is among the top three Salmonella serovars isolated from humans when poultry products were linked to the infection (39-42). Furthermore, SH resistant to various antimicrobial agents has been isolated from domestic animals (43-45). In Experiment 2, our results are in agreement with previous publications from our laboratory, showing not only the low invasiveness of $\mathrm{SH}$ for internal organs, but also effectiveness of FloraMax-B $11^{\circledR}$ in reducing $\mathrm{SH}$ intestinal colonization in turkey poults (46). Published studies have also shown that FloraMax ${ }^{\circledR}-\mathrm{B} 11$ increased colonization resistance to Salmonella spp. infections (47-51), reduces idiopathic diarrhea in commercial turkey brooding houses (52), as well as increased performance and reduced costs in poultry production $(53,54)$. In the present study, it was remarkable to observe that poults treated with $50 \mathrm{mg} / \mathrm{kg}$ of Enrofloxacin were more susceptible to $\mathrm{SH}$ colonization and that this effect was associated with a significant reduction in the total number of LAB. Poults treated with $50 \mathrm{mg} / \mathrm{kg}$ of Enrofloxacin showed a significant increase in BW and BWG, however, this group also showed a significant increase in gut permeability. Metagenomic analysis of cecal content using the MEGAN software can be used to interactively analyze and compare metagenomic and metatranscriptomic data, thereby providing a percent identity filter that can be used to enforce the following levels of percentage sequence identities for an assignment at a given taxonomic level (25). In Experiment 2 , poults treated with Enrofloxacin had a lower proportion of Firmicutes and Bacteroidetes, suggesting that the broad spectrum of Enrofloxacin had a profound impact upon the microbiome. Interestingly, these poults had the highest proportion of Proteobacteria (similar to control). Such a high dose of antibiotic also had a significant increase in Gammaproteobacteria. Changes in the proportion of phylum and class were associated with higher SH intestinal colonization since Salmonella belongs to phylum Proteobacteria, class Gammaproteobacteria. Furthermore, poults treated with Enrofloxacin had lower proportions of Clostridia and Bacilli when compared with control or probiotic poults. Antibiotics administered in low doses have been widely used as growth promoters in poultry for over half a century. However, the exact mechanisms for this effect are elusive. Similarly, there are no reports that have described the impact of Enrofloxacin at low or high therapeutic dose on the microbiome or metabolomics in poultry. This is the first report that describes profound changes in microbiome of turkey poults that received a high dose of Enrofloxacin, shifting it and making them more susceptible to a $\mathrm{SH}$ experimental challenge.

By contrast, poults that received the probiotic had the highest proportion of Firmicutes and Bacteroidetes, but the lowest amount of Proteobacteria. These birds also showed significant reduction in Gammaproteobacteria, but similar to the control group, a higher proportion in Clostridia and Bacilli. The shift in these bacterial populations had a positive effect on reducing $\mathrm{SH}$ colonization following challenge and confirms our previous research (46).

The results of these experiments suggest that, five times the recommended dose of Enrofloxacin, a broad-spectrum antibiotic can have a negative effect on the microbiome that may be responsible for an enhancement of $\mathrm{SH}$ colonization, which has been previously demonstrated with other enteropathogens (4, $28,29,31,32)$. The mechanism of antibiotic-altered resistance was not investigated in the present study. However, regardless 
of the mechanism involved, increased susceptibility of turkey poults to Salmonella was observed in two experiments following Enrofloxacin treatment. Furthermore, based on the microbiota changes following fluoroquinolone administration, including the increase in Proteobacteria, these results suggest that this practice may predispose to other infectious diseases that will further require the use of additional antibiotics and broaden the selection of antimicrobial resistance. Acquisition of resistance to fluoroquinolones has been reported to be a multifaceted process, which includes spontaneous point mutations that result in amino acid substitutions within the topoisomerase subunits GyrA, GyrB, ParC, or ParE, reduced expression of outer membrane porins, overexpression of multidrug efflux pumps, and/or plasmid-mediated quinolone resistance $(1,2,7,13,15,55,56)$. It is remarkable to contemplate that the alarming incidence of certain enteric pathogens is associated with the indiscriminate use of some antibiotics in animal agriculture in some countries $(42,45$, 57-61). Since poultry products have been identified as important reservoirs of human infections, this is a growing public health concern. Given that fluoroquinolones and other antibiotics are

\section{REFERENCES}

1. Piddock L, Whale K, Wise R. Quinolone resistance in Salmonella: clinical experience. Lancet (1990) 335:1459. doi:10.1016/0140-6736(90)91484-R

2. Engberg J, Aarestrup FM, Taylor DE, Gerner-Smidt P, Nachamkin I. Quinolone and macrolide resistance in Campylobacter jejuni and C. coli: resistance mechanisms and trends in human isolates. Emerg Infect Dis (2001) 7:24-34. doi:10.3201/eid0701.010104

3. Murray BE. Resistance of Shigella, Salmonella, and other selected enteric pathogens to antimicrobial agents. Rev Infect Dis (1986) 8:S172-81. doi:10.1093/clinids/8.Supplement_2.S172

4. Uwaydah A, Matar I, Chacko K, Davidson J. The emergence of antimicrobial resistant Salmonella typhi in Qatar: epidemiology and therapeutic implications. Trans R Soc Trop Med Hyg (1991) 85:790-2. doi:10.1016/0035-9203(91) 90457-A

5. Griggs D, Hall M, Jin Y, Piddock LJ. Quinolone resistance in veterinary isolates of Salmonella. J Antimicrob Chemother (1994) 33:1173-89. doi:10.1093/ jac/33.6.1173

6. Bager F, Helmuth R. Epidemiology of resistance to quinolones in Salmonella. Vet Res (2001) 32:285-90. doi:10.1051/vetres:2001125

7. Alfredson DA, Korolik V. Antibiotic resistance and resistance mechanisms in Campylobacter jejuni and Campylobacter coli. FEMS Microbiol Lett (2007) 277:123-32. doi:10.1111/j.1574-6968.2007.00935.x

8. Couper M. Strategies for the rational use of antimicrobials. Clin Infect Dis (1997) 24:S154-6. doi:10.1093/clinids/24.Supplement_1.S154

9. Rodrigue D, Tauxe R, Rowe B. International increase in Salmonella Enteritidis: a new pandemic? Epidemiol Infect (1990) 105:21-7. doi:10.1017/ S0950268800047609

10. Mead PS, Slutsker L, Dietz V, McCaig LF, Bresee JS, Shapiro C, et al. Foodrelated illness and death in the United States. Emerg Infect Dis (1999) 5:607-25. doi:10.3201/eid0505.990502

11. Randall LP, Cooles SW, Coldham NC, Stapleton KS, Piddock LJ, Woodward MJ. Modification of enrofloxacin treatment regimens for poultry experimentally infected with Salmonella enterica serovar Typhimurium DT104 to minimize selection of resistance. Antimicrob Agents Chemother (2006) 50:4030-7. doi:10.1128/AAC.00525-06

12. Castanon J. History of the use of antibiotic as growth promoters in European poultry feeds. Poult Sci (2007) 86:2466-71. doi:10.3382/ps.2007-00249

13. Piddock L, Wise R. Mechanisms of resistance to quinolones and clinical perspectives. J Antimicrob Chemother (1989) 23:475-80. doi:10.1093/jac/23.4.475

14. Acar JF, Goldstein FW. Trends in bacterial resistance to fluoroquinolones. Clin Infect Dis (1997) 24(Suppl 1):S67-73. doi:10.1093/clinids/24.Supplement_1.S67 over used in animal production, any effort to diminish the risk of resistance is crucial. The results of the present study and of previous investigations involving antibiotics and other enteropathogens suggest that prophylactic utilization of some antibiotics in poultry increase the susceptibility to salmonellae colonization and organ invasion. Therefore, antibiotics should be limited to infections of specific bacteria with known antibiotic sensitivity. In addition, our findings also confirm previous studies suggesting that the use of alternatives, such as probiotics, can be an effective tool in controlling salmonellae infections.

\section{AUTHOR CONTRIBUTIONS}

EM-B, NC, JL-T, and VL: conception and design, acquisition of data, and drafting of manuscript. XH-V, JL, BH, GT: drafting the article and revising it critically for important intellectual content. OP-R, RM-G, VP-G, AW, MB, BM, KT, and LG: acquisition of data. BH and GT: analysis and interpretation of data, drafting of manuscript, and approval of the version to be submitted and any revised version.

15. Piddock LJ. Fluoroquinolone resistance in Salmonella serovars isolated from humans and food animals. FEMS Microbiol Rev (2002) 26:3-16. doi:10.111 1/j.1574-6976.2002.tb00596.x

16. Sierra-Arguello Y, Faulkner O, Tellez G, Hargis B, Pinheiro do Nascimento V. The use of FTA cards for transport and detection of gyrA mutation of Campylobacter jejuni from poultry. Poult Sci (2016) 95:798-801. doi:10.3382/ ps/pev384

17. Menconi A, Kallapura G, Latorre JD, Morgan MJ, Pumford NR, Hargis BM, et al. Identification and characterization of lactic acid bacteria in a commercial probiotic culture. Biosci Microbiota Food Health (2014) 33:25-30. doi:10.12938/bmfh.33.25

18. National Research Council. Nutrient Requirements of Poultry. 9th ed. Washington, DC: National Academic Press (1994).

19. Yan Y, Kolachala V, Dalmasso G, Nguyen H, Laroui H, Sitaraman SV, et al. Temporal and spatial analysis of clinical and molecular parameters in dextran sodium sulfate induced colitis. PLoS One (2009) 4:e6073. doi:10.1371/journal. pone.0006073

20. Kuttappan V, Berghman L, Vicuña E, Latorre J, Menconi A, Wolchok J, et al. Poultry enteric inflammation model with dextran sodium sulfate mediated chemical induction and feed restriction in broilers. Poult Sci (2015) 94:1220-6. doi:10.3382/ps/pev114

21. Vicuña E, Kuttappan V, Galarza-Seeber R, Latorre J, Faulkner O, Hargis B, et al. Effect of dexamethasone in feed on intestinal permeability, differential white blood cell counts, and immune organs in broiler chicks. Poult Sci (2015) 94:2075-80. doi:10.3382/ps/pev211

22. Vicuña E, Kuttappan V, Tellez G, Hernandez-Velasco X, Seeber-Galarza R, Latorre J, et al. Dose titration of FITC-D for optimal measurement of enteric inflammation in broiler chicks. Poult Sci (2015) 94:1353-9. doi:10.3382/ps/ pev111

23. Degnan PH, Ochman H. Illumina-based analysis of microbial community diversity. ISME J (2012) 6:183-94. doi:10.1038/ismej.2011.74

24. Cole JR, Wang Q, Cardenas E, Fish J, Chai B, Farris RJ, et al. The Ribosomal Database Project: improved alignments and new tools for rRNA analysis. Nucleic Acids Res (2009) 37:D141-5. doi:10.1093/nar/gkn879

25. Huson DH, Weber N. Microbial community analysis using MEGAN. Methods Enzymol (2013) 531:465-85. doi:10.1016/B978-0-12-407863-5.00021-6

26. SAS Institute. SAS User Guide. Version 9.1. Cary, NC: SAS Institute Inc (2002).

27. Zar J. Biostatistical Analysis. 2nd ed. Upper Saddle River, NJ: Prentice Hall (1984).

28. Aserkoff B, Bennett JV. Effect of antibiotic therapy in acute salmonellosis on the fecal excretion of salmonellae. N Engl J Med (1969) 281:636-40. doi:10.1056/NEJM196909182811202 
29. Rantala M, Nurmi E. Hazards involved in the use of furazolidone for the prevention of salmonellosis in broiler chickens. J Hyg (1974) 72:349-54. doi:10.1017/S0022172400023573

30. Smith HW, Tucker JF. The effect of antibiotic therapy on the faecal excretion of Salmonella typhimurium by experimentally infected chickens. J Hyg (1975) 75:275-92. doi:10.1017/S0022172400047318

31. Manning J, Hargis B, Hinton A Jr, Corrier D, DeLoach J, Creger C. Effect of nitrofurazone or novobiocin on Salmonella Enteritidis cecal colonization and organ invasion in leghorn hens. Avian Dis (1992) 36:334-40. doi:10.2307/1591508

32. Manning J, Hargis B, Hinton A Jr, Corrier D, DeLoach J, Creger C. Effect of selected antibiotics and anticoccidials on Salmonella Enteritidis cecal colonization and organ invasion in Leghorn chicks. Avian Dis (1994) 38:256-61. doi:10.2307/1591946

33. Seuna E, Nurmi E. Therapeutical trials with antimicrobial agents and cultured cecal microflora in Salmonella infantis infections in chickens. Poult Sci (1979) 58:1171-4. doi:10.3382/ps.0581171

34. Niewold T. The nonantibiotic anti-inflammatory effect of antimicrobial growth promoters, the real mode of action? A hypothesis. Poult Sci (2007) 86:605-9. doi:10.1093/ps/86.4.605

35. Bartlett JG. Antibiotic-associated diarrhea. N Engl J Med (2002) 346:334-9. doi:10.1056/NEJMcp011603

36. Hinton A Jr, Corrier DE, Spates GE, Norman JO, Ziprin RL, Beier RC, et al. Biological control of Salmonella typhimurium in young chickens. Avian Dis (1990) 34:626-33. doi:10.2307/1591255

37. Van Der Wielen PW, Biesterveld S, Notermans S, Hofstra H, Urlings BA, van Knapen F. Role of volatile fatty acids in development of the cecal microflora in broiler chickens during growth. Appl Environ Microbiol (2000) 66:2536-40. doi:10.1128/AEM.66.6.2536-2540.2000

38. Corrier DE, Hinton A Jr, Ziprin RL, Beier RC, DeLoach JR. Effect of dietary lactose on cecal $\mathrm{pH}$, bacteriostatic volatile fatty acids, and Salmonella typhimurium colonization of broiler chicks. Avian Dis (1990) 34:617-25. doi:10.2307/1591254

39. Currie A, MacDougall L, Aramini J, Gaulin C, Ahmed R, Isaacs S. Frozen chicken nuggets and strips and eggs are leading risk factors for Salmonella Heidelberg infections in Canada. Epidemiol Infect (2005) 133:809-16. doi:10.1017/S0950268805004383

40. Bucher O, Holley RA, Ahmed R, Tabor H, Nadon C, Ng LK, et al. Occurrence and characterization of Salmonella from chicken nuggets, strips, and pelleted broiler feed. J Food Prot (2007) 70:2251-8.

41. Dutil L, Irwin R, Finley R, Ng LK, Avery B, Boerlin P, et al. Ceftiofur resistance in Salmonella enterica serovar Heidelberg from chicken meat and humans. Canada Emerg Infect Dis (2010) 16:48-54. doi:10.3201/eid1601.090729

42. Vaz C, Streck A, Michael G, Marks F, Rodrigues D, Dos Reis E, et al. Antimicrobial resistance and subtyping of Salmonella enterica subspecies enterica serovar Enteritidis isolated from human outbreaks and poultry in southern Brazil. Poult Sci (2010) 89:1530-6. doi:10.3382/ps.2009-00453

43. Patchanee P, Zewde BM, Tadesse DA, Hoet A, Gebreyes WA. Characterization of multidrug-resistant Salmonella enterica serovar Heidelberg isolated from humans and animals. Foodborne Pathog Dis (2008) 5:839-51. doi:10.1089/ fpd.2008.0149

44. Zhao S, White D, Friedman S, Glenn A, Blickenstaff K, Ayers S, et al. Antimicrobial resistance in Salmonella enterica serovar Heidelberg isolates from retail meats, including poultry, from 2002 to 2006. Appl Environ Microbiol (2008) 74:6656-62. doi:10.1128/AEM.01249-08

45. Borsoi A, Santin E, Santos L, Salle C, Moraes H, Nascimento V. Inoculation of newly hatched broiler chicks with two Brazilian isolates of Salmonella Heidelberg strains with different virulence gene profiles, antimicrobial resistance, and pulsed field gel electrophoresis patterns to intestinal changes evaluation. Poult Sci (2009) 88:750-8. doi:10.3382/ps.2008-00466

46. Menconi A, Wolfenden A, Shivaramaiah S, Terraes J, Urbano T, Kuttel J, et al. Effect of lactic acid bacteria probiotic culture for the treatment of Salmonella enterica serovar Heidelberg in neonatal broiler chickens and turkey poults. Poult Sci (2011) 90:561-5. doi:10.3382/ps.2010-01220

47. Higgins J, Higgins S, Vicente J, Wolfenden A, Tellez G, Hargis B. Temporal effects of lactic acid bacteria probiotic culture on Salmonella in neonatal broilers. Poult Sci (2007) 86:1662-6. doi:10.1093/ps/86.8.1662
48. Vicente J, Higgins S, Bielke L, Tellez G, Donoghue D, Donoghue A, et al. Effect of probiotic culture candidates on Salmonella prevalence in commercial turkey houses. J Appl Poult Res (2007) 16:471-6. doi:10.1093/japr/16.3.471

49. Tellez G, Pixley C, Wolfenden R, Layton S, Hargis B. Probiotics/direct fed microbials for Salmonella control in poultry. Food Res Int (2012) 45:628-33. doi:10.1016/j.foodres.2011.03.047

50. Biloni A, Quintana C, Menconi A, Kallapura G, Latorre J, Pixley C, et al. Evaluation of effects of EarlyBird associated with FloraMax-B11 on Salmonella Enteritidis, intestinal morphology, and performance of broiler chickens. Poult Sci (2013) 92:2337-46. doi:10.3382/ps.2013-03279

51. Menconi A, Hernandez-Velasco X, Latorre JD, Kallapura G, Pumford NR, Morgan MJ, et al. Effect of Chitosan as a biological sanitizer for Salmonella typhimurium and aerobic Gram negative spoilage bacteria present on chicken skin. Int J Poult Sci (2013) 12:318-21. doi:10.3923/ijps.2013.318.321

52. Higgins S, Torres-Rodriguez A, Vicente J, Sartor C, Pixley C, Nava G, et al. Evaluation of intervention strategies for idiopathic diarrhea in commercial turkey brooding houses. J Appl Poult Res (2005) 14:345-8. doi:10.1093/ japr/14.2.345

53. Torres-Rodriguez A, Higgins S, Vicente J, Wolfenden A, Gaona-Ramirez G, Barton J, et al. Effect of lactose as a prebiotic on turkey body weight under commercial conditions. J Appl Poult Res (2007) 16:635-41. doi:10.3382/ japr.2006-00127

54. Vicente JL, Torres-Rodriguez A, Higgins SE, Pixley C, Tellez G, Donoghue AM, et al. Effect of a selected Lactobacillus spp.-based probiotic on Salmonella enterica serovar Enteritidis-infected broiler chicks. Avian Dis (2008) 52:143-6. doi:10.1637/7847-011107-ResNote

55. Angulo FJ, Johnson KR, Tauxe RV, Cohen ML. Origins and consequences of antimicrobial-resistant nontyphoidal Salmonella: implications for the use of fluoroquinolones in food animals. Microb Drug Resist (2000) 6:77-83. doi: $10.1089 / \mathrm{mdr} .2000 .6 .77$

56. Crump JA, Medalla FM, Joyce KW, Krueger AL, Hoekstra RM, Whichard JM, et al. Antimicrobial resistance among invasive nontyphoidal Salmonella enterica in the United States, national antimicrobial resistance monitoring system, 1996-2007. Antimicrob Agents Chemother (2011) 55:1148-54. doi:10.1128/ AAC.01333-10

57. Hofer E, dos Reis EMF. Salmonella serovars in food poisoning episodes recorded in Brazil from 1982 to 1991. Rev Inst Med Trop São Paulo (1994) 36:7-9.

58. Irino K, Fernandes S, Tavechio A, Neves B, Dias A. Progression of Salmonella Enteritidis phage type 4 strains in São Paulo State, Brazil. Rev Inst Med Trop São Paulo (1996) 38:193-6.

59. Tavechio AT, Ghilardi AC, Fernandes SA. "Multiplex PCR" identification of the atypical and monophasic Salmonella enterica subsp. enterica serotype 1, 4,[5], 12: i:-in São Paulo State, Brazil: frequency and antibiotic resistance patterns. Rev Inst Med Trop São Paulo (2004) 46:115-7. doi:10.1590/ S0036-46652004000200012

60. Peirano G, Agersø Y, Aarestrup FM, dos Reis EMF, dos Prazeres Rodrigues D. Occurrence of integrons and antimicrobial resistance genes among Salmonella enterica from Brazil. J Antimicrob Chemother (2006) 58:305-9. doi:10.1093/ $\mathrm{jac} / \mathrm{dkl} 248$

61. De Moura HM, Silva PR, da Silva PHC, Souza NR, Racanicci AMC, Santana ÂP. Antimicrobial resistance of Campylobacter jejuni isolated from chicken carcasses in the Federal District, Brazil. J Food Prot (2013) 76:691-3. doi:10.4315/0362-028X.JFP-12-485

Conflict of Interest Statement: The authors declare that the research was conducted in the absence of any commercial or financial relationships that could be construed as a potential conflict of interest.

Copyright (C) 2016 Morales-Barrera, Calhoun, Lobato-Tapia, Lucca, PradoRebolledo, Hernandez-Velasco, Merino-Guzman, Petrone-García, Latorre, Mahaffey, Teague, Graham, Wolfenden, Baxter, Hargis and Tellez. This is an open-access article distributed under the terms of the Creative Commons Attribution License (CC BY). The use, distribution or reproduction in other forums is permitted, provided the original author(s) or licensor are credited and that the original publication in this journal is cited, in accordance with accepted academic practice. No use, distribution or reproduction is permitted which does not comply with these terms. 